Review

\title{
Advances in generation of three-dimensional skin equivalents: pre-clinical studies to clinical therapies
}

\author{
Subholakshmi Choudhury ${ }^{1,2}$, Amitava Das ${ }^{1,2, *}$ \\ ${ }^{1}$ Department of Applied Biology, Council of Scientific and Industrial Research-Indian Institute of Chemical Technology, Hyderabad, India \\ ${ }^{2}$ Academy of Scientific and Innovative Research, Council of Scientific and Industrial Research-Indian Institute of Chemical Technology, Hyderabad, India
}

\section{A R T I C L E I N F O}

\section{Article History:}

Received 16 June 2020

Accepted 9 October 2020

\section{Key Words:}

skin anatomy and physiology

skin diseases

skin equivalents

$3 \mathrm{D}$ cell culture

tissue engineering

wound tissue regeneration

\begin{abstract}
A B S T R A C T
The inability of two-dimensional cell culture systems to adequately map the structure and function of complex organs like skin necessitates the development of three-dimensional (3D) skin models. A diverse range of 3D skin equivalents have been developed over the last few decades for studying complex properties of skin as well as for drug discovery and clinical applications for skin regeneration in chronic wounds, such as diabetic foot ulcers, where the normal mechanism of wound healing is compromised. These 3D skin substitutes also serve as a suitable alternative to animal models in industrial applications and fundamental research. With the emergence of tissue engineering, new scaffolds and matrices have been integrated into 3D cell culture systems, along with gene therapy approaches, to increase the efficacy of transplanted cells in skin regeneration. This review summarizes recent approaches to the development of skin equivalents as well as different models for studying skin diseases and properties and current therapeutic applications of skin substitutes.
\end{abstract}

(C) 2020 International Society for Cell \& Gene Therapy. Published by Elsevier Inc. All rights reserved.

\section{Introduction}

Skin, the largest organ of the human body, performs crucial functions, such as thermoregulation, excretion, absorption and pigmentation as well as physical and immunological barrier function. The skin consists of multiple layers, which can be broadly classified into epidermis, dermis and hypodermis. Epidermis, the outermost layer, primarily consists of keratinocytes [1]. The dermis lies beneath the epidermis, separated by a basement membrane. Fibroblasts constitute the major population of cells in the dermal layer. Keratinocyte stem cells of the basal layer undergo terminal differentiation via several discrete transcriptional stages during the formation of the epidermis, resulting in four distinguishable layers: stratum basale, stratum spinosum, stratum granulosum and stratum corneum [2].

Although two-dimensional (2D) cell culture systems have been primarily used for studying cell morphology and molecular interactions as well as for drug discovery and regenerative therapy, threedimensional (3D) culture systems provide a better representation of complex structures such as skin. Unlike 2D culture systems, cells in 3D culture systems are morphologically and physiologically very similar to in vivo systems, making them a potential replacement for organ transplantation. Historically, the 3D skin culture began in the

\footnotetext{
* Correspondence: Amitava Das, PhD, Department of Applied Biology, Council of Scientific and Industrial Research-Indian Institute of Chemical Technology, Uppal Road, Tarnaka, Hyderabad, 500 007, Telangana State, India.

E-mail addresses: amitavadas@iict.res.in, amitavadas.iict@gov.in (A. Das).
}

middle of the 20th century, when human skin biopsies were first cultured [3]. This "organ culture" system, though it provided an ideal physiological construct, was challenged by several limitations, such as inadequate tissue availability, donor variability and ethical issues. In 1981, Bell et al. [4] developed the tissue-engineered 3D human skin equivalent, consisting of dermal and epidermal layers.

This review focuses on various 3D cell culture techniques used to generate skin equivalents, their limitations and recent advancements. Moreover, this review highlights the existing in vitro models to study the physiological properties of skin, various disease models and the application of skin equivalents in wound repair and regeneration.

\section{Three-dimensional cell culture techniques for developing skin equivalents}

Skin equivalents are artificially reconstructed skin substitutes composed of epidermal and dermal layers. Skin equivalents are designed to closely resemble native skin and can be developed from primary cells (keratinocytes, fibroblasts and/or stem cells) and components of the extracellular matrix (ECM). Over the last few decades, there has been a tremendous increase in research and development of skin equivalents for fundamental research as well as industrial and clinical applications.

\section{Spheroid model}

Spheroids are 3D cellular aggregates that can represent the actual microenvironment of cells more accurately when compared with 2D 
a.

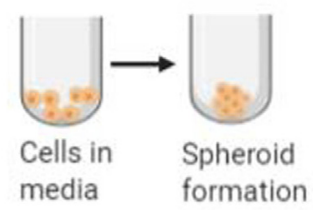

b.

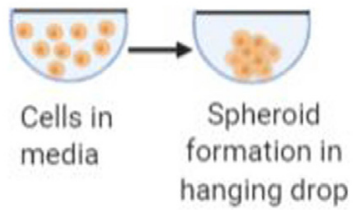

Figure 1. Schematic representation of spheroid culture of skin equivalents. (A) Spheroid cell culture showing spontaneous formation of spheroids on low adhesion, roundbottom surface [6]. (B) Hanging drop culture shows an inverted plate with a drop of cell suspension [5]. In both methods, cells gradually form spheroids. (Color version of figure is available online).

cell cultures. The most common method of spheroid culture is the hanging drop method, in which droplets having a high density of cells are cultured in inverted cell culture plates under physiological conditions until they form 3D spheroids (Figure 1A). In this method, cells are in direct contact with each other and the ECM components. This method has been further modified by adding biological agents or by co-culturing two or more cell types [5]. Some studies have also reported variations in the spheroid culturing method by using nonadherent U-shaped bottom plates (Figure 1B). However, the use of spheroid culture is very uncommon in skin research. Until now, very few studies have reported culturing keratinocyte and fibroblast cell lines as spheroids. A recent study showed generation of spheroids by co-culturing three types of cells on a low attachment surface; type IV collagen-rich fibroblasts formed the core, surrounded by a ring of keratinocytes with melanoma cells on the outside [6]. However, in such models, complete differentiation of keratinocytes for the formation of the stratified epithelium has not been observed.

\section{Layered co-cultured cells using scaffold-free and scaffold-based models}

Skin equivalents can be formed using a layer-by-layer co-culture of fibroblasts and keratinocytes. Most of the co-cultures are raised to an air-liquid interface to facilitate the stratification of the epithelial layer, which consists of keratinocytes (Figure 2A). Both scaffold-free

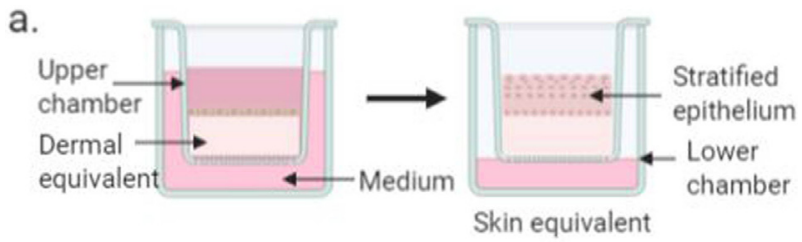

b.

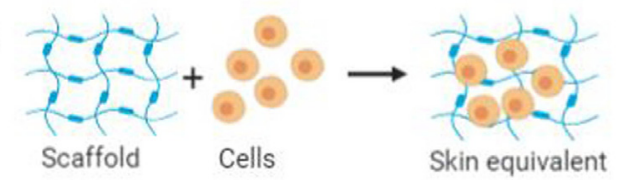

Figure 2. Organotypic co-culture of skin cells. (A) Layer-by-layer co-culture of skin equivalents on a transwell plate. Upper chamber contains the dermal equivalent seeded with epidermal cells, which is raised to an air-liquid interface for the formation of stratified epithelium. Lower chamber contains the culture medium [7,8]. (B) Cells seeded on a polymer scaffold to form skin equivalents. Cells penetrate inside the scaffold and undergo proliferation and differentiation, which leads to increased production of growth factors and cytokines [12-19]. (Color version of figure is available online). and scaffold-based protocols have been described in the literature. The process of tissue engineering involves the use of bioengineered scaffolds, chemical compounds and growth factors combined with cells to develop viable biological substitutes (Figure 2B).

Michel et al.[7] designed a skin equivalent exclusively from cultured fibroblasts and keratinocytes without the use of any synthetic material. In the presence of ascorbic acid, collagen secretion by fibroblasts was increased, giving rise to a well-organized dermal layer. The ECM was formed by endogenous secretion of fibroblasts and keratinocytes seeded on the dermal layer that formed a stratified epithelium when raised to an air-liquid interface. In a scaffold-free technique demonstrated by Liu et al. [8], fibroblasts and endothelial cells were co-cultured and induced to secrete their own ECM, leading to the formation of a dermal substitute. Subsequently, keratinocytes were overlaid on the dermal substitute to form a bilayer skin equivalent. Instead of using preformed exogenous scaffolds, fibroblasts and keratinocytes have also been coated with ECM components like collagen, fibronectin and gelatin, which induce the cells to produce ECM to form skin equivalents [9,10]. Natural biomaterials like collagen, chitosan, hyaluronic acid, gelatin and fibrin have been commonly used as scaffolds for the generation of skin equivalents. Casale et al.[11] described a method in which human fibroblasts were cultured on gelatin microscaffolds in dynamic bioreactors until they formed human dermis equivalents composed of fibroblasts embedded in their own ECM. Epidermal cells were then cultured on the surface of the human dermis equivalent. Collagen is a major protein in ECM, and collagen-based biomaterials that serve as ECM analogs have been reported to promote vascularization both in vitro and in vivo during reconstruction of skin tissues [12]. A study by Reuter et al.[13] has shown the use of collagen type 1-based hydrogel as a scaffold for culturing fibroblasts and keratinocytes to form a full-thickness skin equivalent. To increase their efficiency, natural polymers are often combined either together or with synthetic polymers along with chemical modifications that can improve properties such as porosity and biocompatibility as well as processability. Liu et al.[14] cross-linked chitosan, gelatin and hyaluronic acid to form a composite scaffold and subsequently demonstrated the formation of artificial skin by co-culturing keratinocytes and fibroblasts on the scaffold. In another study, keratin, fibrin and gelatin were blended to fabricate a scaffold that could enhance the cell growth of fibroblasts and keratinocytes. The drug mupirocin was incorporated in the scaffold to impart antibacterial properties [15].

Synthetic polymer scaffolds are widely used in the skin tissue engineering process. Most of them are hydrocarbon polymers like polylactic acid (PLA), polyglycolic acid (PGA), polyethylene glycol (PEG) and poly(lactic-co-glycolic acid) (PLGA) (Table 1). These polymers have been used in combination with natural biomaterials like collagen or chitosan to form scaffolds that are suitable for skin equivalent formation. Shalumon et al.[16] synthesized a combined scaffold of PLA and chitosan with aligned nanofibers and observed higher

Table 1

List of commonly used biosynthetic polymer scaffolds for skin tissue engineering.

\begin{tabular}{|c|c|c|}
\hline Name & Composition & Properties \\
\hline PLA [16] & Polylactic acid polymers & $\begin{array}{l}\text { Biodegradable, biocompati- } \\
\text { ble, good mechanical } \\
\text { properties, porous } \\
\text { structure }\end{array}$ \\
\hline PGA [17] & Polyglycolic acid polymers & $\begin{array}{l}\text { Biodegradable, } \\
\text { thermoplastic }\end{array}$ \\
\hline PLGA [18] & Poly(lactic-co-glycolic acid) & $\begin{array}{l}\text { Good mechanical properties, } \\
\text { porous structure, elastic in } \\
\text { nature, easy processability }\end{array}$ \\
\hline PEG $[18,19]$ & $\begin{array}{l}\text { Polyethylene glycol } \\
\text { polymers }\end{array}$ & $\begin{array}{l}\text { Biodegradable, porous scaf- } \\
\text { folds, low inflammatory } \\
\text { response }\end{array}$ \\
\hline PEG-PU [19] & $\begin{array}{l}\text { Polyethylene glycol- } \\
\text { polyurethane }\end{array}$ & $\begin{array}{l}\text { High porosity, biocompati- } \\
\text { bility, biodegradability }\end{array}$ \\
\hline
\end{tabular}


biodegradability when compared with pure PLA scaffold. A composite scaffold of PGA and collagen demonstrated increased neovascularization and migratory potential of cells after transplantation in the wound defect model of $d b / d b$ mice [17]. A composite triblock of PEG and PLGA scaffolds (PEG-PLGA-PEG) along with muscle-derived stem cells was transplanted in a wound model of diabetic mice. The use of the scaffold was shown in another study to result in increased engraftment of muscle-derived stem cells and to facilitate wound healing by retaining the cells at the wound site for a longer period of time [18]. A porous PEG-polyurethane (PEG-PU) scaffold was designed that demonstrated properties like high porosity, biocompatibility and biodegradability. Accelerated wound healing was observed when PEG-PU scaffolds seeded with mouse bone marrowderived stem cells were transplanted in a murine excisional splint wound model. The PEG-PU scaffold has the potential to serve as an excellent biomaterial for skin equivalent formation [19]. In a study by Roger et al.[20], human dermal fibroblasts were seeded on a porous polystyrene membrane (Alvetex ${ }^{\circledR}$ scaffolds) for the generation of dermal models, followed by seeding human keratinocytes onto dermal equivalents. Though skin equivalents developed through tissue engineering processes are the physiologically most relevant in vitro models, major disadvantages include high costs and time-consuming protocols. Moreover, very few studies have reported the development of a functional full-thickness in vitro skin suitable for transplantation in disease models.

\section{Bioprinting}

Using a bioprinting technique, tissues and organs can be fabricated by precisely positioning living cells, biological materials and biochemicals with the help of a computer-controlled 3D printer (Figure $3 \mathrm{~A}-\mathrm{C}$ ). There are three main types of bioprinting technologies: microextrusion-based, inkjet-based and laser-assisted printing $[21,22,23]$. These 3D bioprinting technologies have been extensively used to produce multilayered skin. Kim et al.[24] developed a hybrid bioprinting system-also known as an integrated composite tissue or organ building system-in which extrusion-based and inkjet-based techniques were combined and used simultaneously to construct 3D skin equivalents with a printable, functional transwell system. The extrusion module was used to construct the dermal layer, and the inkjet module was used to construct the epidermis. To further increase the complexity of 3D printed skin, a hypodermal compartment was constructed using adipose-fibrinogen hybrid bioink, and vascular channels were printed using human umbilical vein endothelial cells and thrombin-embedded gelatin hydrogel-based bioink [25]. Cubo et al.[26] used bioprinting technology to develop a bilayer human skin equivalent on a fibrin matrix. They used human plasma, primary human fibroblasts and keratinocytes obtained from skin biopsies as bioinks. Skin-derived extracellular matrix has also been

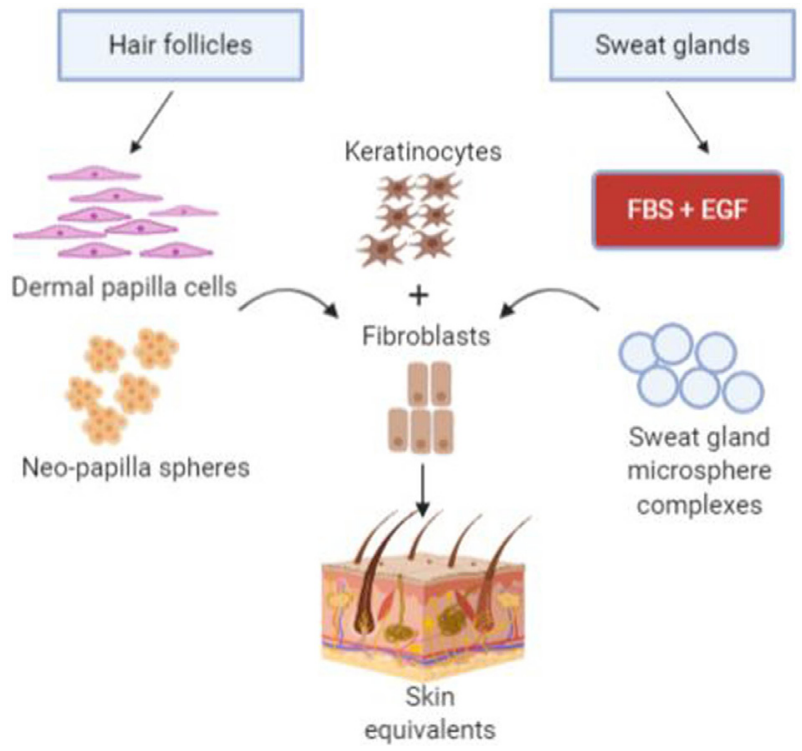

Figure 4. Formation of skin appendages in skin equivalents. Hair follicles were generated by culturing dermal papilla cells [30] or neo-papilla spheroids [31] from aggregated dermal papilla cells along with keratinocytes and fibroblasts. Sweat gland formation was observed in the presence of FBS and EGF [32] or by incorporating sweat gland microspheres into the engineered skin constructs [33]. EGF, epidermal growth factor; FBS, fetal bovine serum. (Color version of figure is available online).

used as a printable bioink to enhance the stability of skin equivalents [27]. Recent studies have developed bioprinted skin equivalents that can replicate various properties of native skin-like pigmentation and barrier function (Figure 4) [28,29].

\section{Three-dimensional models for studying skin anatomy and physiology}

The ability of 3D skin models to mimic in vivo cellular responses makes them instrumental in understanding the unique properties of the skin.

\section{Morphogenesis of skin appendages}

The skin contains various adnexal structures, including hair follicles, sweat glands and sebaceous glands. Hair follicles reside in the dermal layer of skin and play a crucial role in thermoregulation and dispersion of sweat and sebum as well as in sensory and tactile functions. A recent study by Lalley and Boyce [30] demonstrated the generation of a chimeric skin substitute with hair follicles by culturing murine dermal papillae cells along with human fibroblasts and keratinocytes on collagen-glycosaminoglycan scaffolds, which generated hair follicles after transplantation into full-thickness wounds of

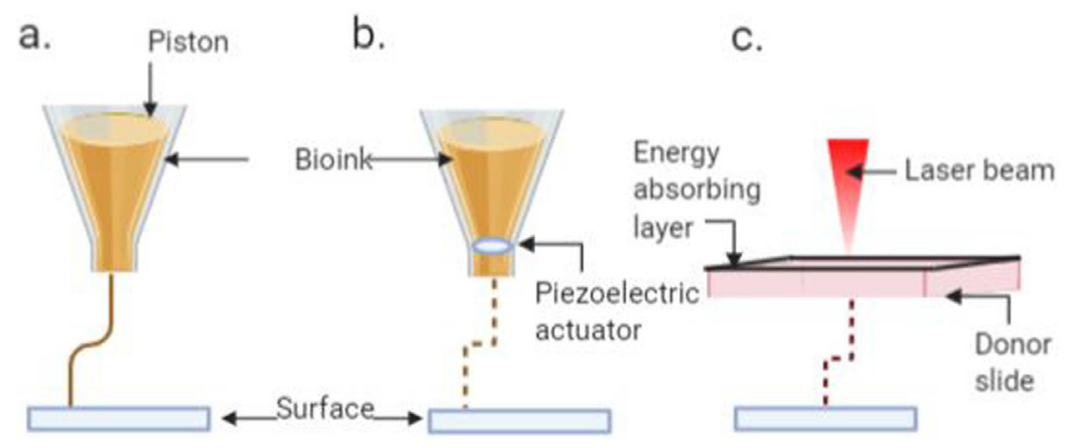

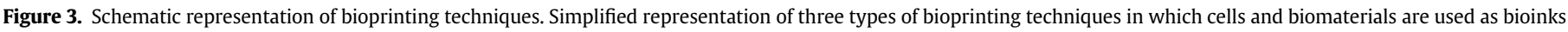

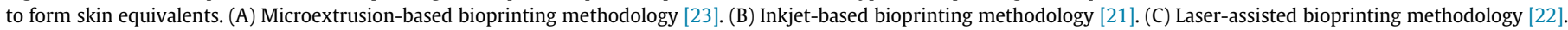
(Color version of figure is available online). 
immunodeficient mice. Vahav et al.[31] described the morphogenesis of hair follicle formation in reconstructed human skin by incorporating neo-papillae spheroids constructed from self-aggregating dermal papillae cells into the dermis of reconstructed human skin. The neopapillae were engulfed through epidermal invagination, demonstrating the first steps of hair follicle formation.

Sweat glands play essential roles in the thermoregulation and homeostasis of the skin. Several studies have demonstrated the importance of epidermal growth factor in the development of eccrine sweat glands. It has been observed that postnatal keratinocytes and fibroblasts can give rise to sweat gland-like structures in the skin equivalents in the presence of fetal bovine serum and epidermal growth factor [32]. Huang et al.[33] cultured sweat gland cells in gelatin microspheres to form sweat gland microsphere complexes, which were then incorporated into engineered skin constructs. These complexes were later differentiated into sweat gland-like structures.

\section{Skin aging}

Skin equivalents have also been used to demonstrate how senescence affects skin morphology and functionality. A study by Diekmann et al.[34] demonstrated aspects of skin aging-like reduced filaggrin expression in the epidermis and lowered elastin and collagen in dermal tissue. In an in vitro setup, senescence was induced by mitomycin C, known to accelerate senescence in fibroblasts, in a skin equivalent model. Weinmüllner et al. [35] constructed a full-thickness skin equivalent model by seeding increasing ratios of stressinduced premature senescent versus normal fibroblasts into a collagen matrix. Several changes, such as partial impairment of skin barrier and changed surface properties as well as a shift in the balance between proliferation and differentiation, were observed in the senescent skin equivalent model.

\section{Epithelialization and barrier function of the skin}

The epidermal layer of skin consists of cornified cells embedded in a lipid matrix called the stratum corneum, which serves as a protective barrier against transcutaneous water loss and other physical, chemical and biological irritants. Some studies have reported an altered barrier function in skin equivalents developed in vitro compared with native skin. To counter this, Mieremet et al. [36] cultured skin equivalents in the presence of free fatty acids. By supplementing the culture medium of human skin equivalents with palmitic acid (PA), a saturated free fatty acid, the researchers hoped to understand the role of PA on skin morphogenesis and barrier formation. Improved epidermal morphogenesis was observed in the presence of $\mathrm{PA}$, as it facilitated the proper execution of the early differentiation process in epidermis. However, lipid barrier composition remained the same irrespective of the concentration of PA and was much lower than native skin. This suggested the need for the development of more accurate optimization processes in the future. It has been reported that subjecting human skin equivalents to hypoxia conditions results in reduced epidermal thickness and alters the lipid composition of stratum corneum, better resembling native human skin [37]. Recent studies have revealed the importance of tight junctions present within the epidermal and dermal layers in maintaining cutaneous barrier homeostasis with the help of skin equivalents. It has also been observed that IL-17 impairs the tight junctions in 3D models of atopic dermatitis [38,39]. Another study reported that the treatment of 3D skin models with IL-31 resulted in a disruption of skin barrier properties resembling atopic dermatitis [40]. The researchers further investigated the effects of a ceramide-containing water-in-oil skincare ointment on disrupted skin barrier models. It was observed that the barrier function of skin models recovered after daily topical application of the ointment.

\section{Disease models of skin}

Three-dimensional cultured skin substitutes can replicate the physiological properties of skin accurately. They can be used as an alternative to animal models for studying various disease conditions of the skin.

\section{Psoriasis}

Psoriasis, a chronic autoimmune skin disease, causes scaly, erythematous lesions (Table 2). Psoriasis can be associated with multiple comorbidities, including cardiovascular diseases and arthritis. Threedimensional skin models replicating psoriasis-like conditions have been developed to study the pathology of the disease and prophylactic efficacy of drugs as well as to identify novel targets. The pathophysiology of psoriasis involves a complex interaction between keratinocytes and immune cells. Therefore, to accurately represent the disease condition, $\mathrm{T}$ cells were incorporated into 3D skin models [41,42]. These models were able to mimic the psoriatic epidermal phenotype as well as cytokine and transcription factor profiles. These models also responded to psoriatic drugs, suggesting a potential tool for drug development. A study by Clarysse et al.[43] demonstrated the treatment of 3D psoriatic skin models with tofacitinib, which mitigated psoriasis-like epidermal morphology through inhibition of JAK1/3.

\section{Atopic dermatitis}

Atopic dermatitis (AD), a major public health problem, especially in children, results from genetic, environmental and immunological factors leading to defective epidermal barrier function of the skin (Table 2). Three-dimensional models of skin demonstrating AD-like conditions have been developed repeatedly for pre-clinical studies. Recent studies have reported the development of AD-like characteristics in reconstructed human epidermis after treatment with methylbeta-cyclodextrin, which causes cholesterol depletion in the plasma membrane, followed by IL-4, IL-13 and IL-15 exposure [44,45]. Liu et al.[46] developed an AD-like vascularized full-thickness skin model using a bioprinting technique. A biodegradable PLGA scaffold was used

Table 2

Characteristics of skin diseases that have been reproduced using in vitro 3D skin disease models for studying disease mechanisms, pathophysiology and treatment.

\begin{tabular}{|c|c|c|}
\hline Skin diseases & Characteristics & References \\
\hline Psoriasis & $\begin{array}{l}\text { Autoimmune skin disease characterized } \\
\text { by hyperproliferation of epidermal } \\
\text { keratinocytes, leukocyte infiltration, } \\
\text { aberrant growth and altered epithelial } \\
\text { differentiation. }\end{array}$ & [41-43] \\
\hline Atopic dermatitis & $\begin{array}{l}\text { Chronic inflammatory disease of skin } \\
\text { resulting in hyperplasia and spongio- } \\
\text { sis, increased production of pro- } \\
\text { inflammatory cytokines like IL-4 and } \\
\text { IL-13 and inhibition of filaggrin } \\
\text { synthesis. }\end{array}$ & {$[44-46]$} \\
\hline $\begin{array}{l}\text { Skin cancer (cutaneous } \\
\text { melanoma) }\end{array}$ & $\begin{array}{l}\text { Transformed melanocytes of skin } \\
\text { become hyperproliferative and invade } \\
\text { the dermis through the basement } \\
\text { membrane. }\end{array}$ & {$[47,48]$} \\
\hline Cutaneous candidiasis & $\begin{array}{l}\text { Characterized by pruritic rashes; } \\
\text { erythematous macules; vesicular pus- } \\
\text { tules; and sometimes white, } \\
\text { macerated, desquamated skin. }\end{array}$ & {$[49,50]$} \\
\hline Bacterial colonization & $\begin{array}{l}\text { Pathogenic bacteria such as S. aureus can } \\
\text { cause severe skin infections character- } \\
\text { ized by redness of skin and appearance } \\
\text { of boils, rashes and cellulitis. }\end{array}$ & {$[51,52]$} \\
\hline
\end{tabular}


to form a vascularized dermis. AD-like phenotypes were induced after treatment of the skin equivalents with IL-4.

\section{Skin cancer}

Three-dimensional skin cancer models help to elucidate the dermoepidermal and tumor-stroma interactions during skin cancer (Table 2). The most common in vitro skin cancer model is the melanoma model. Hill et al. [47] developed a 3D human skin equivalent model demonstrating early melanoma invasion by culturing metastatic melanoma cells on fibroblasts containing Alvetex dermal equivalents, followed by seeding of keratinocytes. Recent studies have also suggested the incorporation of melanoma spheroids into pre-formed skin equivalents [48]. Bourland et al. [48] incorporated melanoma spheroids cultured through the hanging drop method into a human skin equivalent model possessing blood and lymphatic vessel microvascularization. Melanoma spheroids were rapidly integrated into the epidermal, dermoepidermal and dermal regions of the reconstructed human skin.

\section{Cutaneous candidiasis}

Cutaneous candidiasis (CC), also known as cutaneous candidosis, is a fungal infection caused by the dimorphic yeast Candida albicans (Table 2). An in vitro model of CC was developed by infecting reconstructed human epidermis with Candida albicansblastospores, which caused hyperkeratosis, scaling and superficial keratin degradation [49]. Secreted aspartyl proteinases were responsible for the infection. It was also observed that the damages induced by Candida albicans blastospores increased in the presence of mechanical or chemical trauma. Treatment of CC reconstructed human epidermis with a liposome formulation of econazole has also been found to be effective against the infection [50].

\section{Bacterial colonization of skin}

Normal human skin is inhabited by a range of commensal as well as pathogenic bacterial species. In vitro models of skin have been used to study the colonization of bacteria on the surface of human skin. Lerebour et al.[51] studied the mechanisms involved in adhesion of Staphylococcus aureus and Staphylococcus epidermidis to the epidermal layer of skin using the reconstructed epidermal model EpiSkin $^{\circledR}$, France. S. aureus is a pathogenic bacteria responsible for skin and soft tissue infections. Colonization of $S$. aureus on skin equivalents results in surface damage (Table 2) [52].

\section{Skin equivalents in wound regeneration}

Skin injuries during burns, accidents and chronic diseases can compromise vital skin functions, leading to morbidity and mortality of the patient. Skin tissue regeneration remains a challenging clinical problem because of the involvement of different cell types and the multilayered structure of skin. Conventional cell transplantation and/ or growth factor-based treatment strategies often remain ineffective because of the harsh microenvironment of the injury site. To overcome the limitations of conventional therapies, many efforts have been made to artificially reconstruct skin substitutes using stem cells as well as terminally differentiated skin cells that are suitable for transplantation. Some skin substitutes have already been used in clinical practices (Table 3). Three-dimensional skin equivalents have

Table 3

List of commonly used bioengineered wound dressings and skin substitutes.

\begin{tabular}{|c|c|c|c|}
\hline Name & Composition & Properties & Applications \\
\hline \multicolumn{4}{|c|}{ Acellular wound dressings } \\
\hline Integra $[64,65]$ & $\begin{array}{l}\text { Inner layer of cross-linked bovine collagen } \\
\text { and glycosaminoglycan and an outer sili- } \\
\text { cone layer }\end{array}$ & $\begin{array}{l}\text { The silicone layer forms a semipermeable } \\
\text { membrane that acts as a physical barrier } \\
\text { preventing water loss and bacterial infec- } \\
\text { tion, and the inner layer acts as ECM and } \\
\text { supports vascularization. The silicone layer } \\
\text { has to be replaced later with a thin skin } \\
\text { sheet graft. }\end{array}$ & $\begin{array}{l}\text { Clinical treatment of third-degree burn } \\
\text { wounds and full-thickness skin wounds } \\
\text { like diabetic foot ulcers. }\end{array}$ \\
\hline Biobrane [66] & $\begin{array}{l}\text { Outer silicone membrane and inner nylon } \\
\text { mesh with porcine collagen }\end{array}$ & $\begin{array}{l}\text { Promotes epithelialization and efficient } \\
\text { barrier function and reduces wound } \\
\text { healing time in burn wound patients. }\end{array}$ & $\begin{array}{l}\text { Widely used as a dressing for burn wounds in } \\
\text { children, superficial burn wounds and } \\
\text { genetic skin diseases like epidermolysis } \\
\text { bullosa. }\end{array}$ \\
\hline \multicolumn{4}{|c|}{ Cellular dermal substitutes } \\
\hline Dermagraft [67] & $\begin{array}{l}\text { Dermal substitute comprising human neona- } \\
\text { tal fibroblasts seeded on a bioabsorbable } \\
\text { polyglycolic acid mesh }\end{array}$ & $\begin{array}{l}\text { Lacks the silicone layer and contains living } \\
\text { fibroblasts. After transplantation, fibro- } \\
\text { blasts proliferate to produce growth factors } \\
\text { and ECM components. }\end{array}$ & $\begin{array}{l}\text { Chronic diabetic foot ulcers and burn } \\
\text { wounds. }\end{array}$ \\
\hline TransCyte $[68,69]$ & $\begin{array}{l}\text { Human neonatal fibroblasts seeded on a } \\
\text { membrane composed of nylon and silicone }\end{array}$ & $\begin{array}{l}\text { Accelerates rate of wound healing and } \\
\text { reduces pain and scar formation. }\end{array}$ & $\begin{array}{l}\text { Commonly used for the treatment of partial- } \\
\text { thickness burn wounds. }\end{array}$ \\
\hline \multicolumn{4}{|c|}{ Cellular bilayer skin substitutes } \\
\hline Apligraf [70,71] & $\begin{array}{l}\text { Bilayer skin equivalent composed of neonatal } \\
\text { fibroblasts seeded on a bovine collagen } \\
\text { matrix and stratified epithelium with } \\
\text { living keratinocytes }\end{array}$ & $\begin{array}{l}\text { Resembles native human skin, produces } \\
\text { growth factors and cytokines and acceler- } \\
\text { ates wound healing rate. }\end{array}$ & $\begin{array}{l}\text { Approved by the Food and Drug Administra- } \\
\text { tion for the treatment of venous leg ulcers } \\
\text { and neuropathic diabetic foot ulcers; also } \\
\text { used in the treatment of } \\
\text { epidermolysis bullosa. }\end{array}$ \\
\hline OrCel [72] & $\begin{array}{l}\text { Bilayer skin substitute composed of alloge- } \\
\text { neic normal human epidermal keratino- } \\
\text { cytes and fibroblasts cultured on type } 1 \\
\text { bovine collagen sponge }\end{array}$ & $\begin{array}{l}\text { The living cells secrete cytokines and growth } \\
\text { factors to accelerate wound healing. OrCel } \\
\text { has low expression levels of HLA-II anti- } \\
\text { gens and does not give rise to an HLA- } \\
\text { cytolytic antibody response in patients. }\end{array}$ & $\begin{array}{l}\text { Used for the treatment of surgical excisions } \\
\text { in epidermolysis bullosa and burn wound } \\
\text { patients. }\end{array}$ \\
\hline StrataGraft $[73,74]$ & $\begin{array}{l}\text { Bilayer stratified skin substitute composed of } \\
\text { cultured human keratinocyte cell line (Nor- } \\
\text { mal Immortal KeratinocyteS, NIKS) and } \\
\text { fibroblasts on non-bovine collagen type } 1\end{array}$ & $\begin{array}{l}\text { Accurately reproduces the structural and } \\
\text { biological properties of native human skin. } \\
\text { StrataGraft is well tolerated by and } \\
\text { non-immunogenic in patients. }\end{array}$ & $\begin{array}{l}\text { Used for the treatment of partial-thickness } \\
\text { burn wounds. }\end{array}$ \\
\hline
\end{tabular}


also been widely used in pre-clinical models of acute and chronic wounds. One of the main advantages of 3D skin equivalents is their ability to simultaneously regenerate damaged dermis and epidermis after a single transplantation procedure. Regeneration of full-thickness excisional splint wounds in murine models has been observed after transplantation of bioengineered skin substitutes.

\section{Role of adult skin cells and stem cells in skin tissue engineering}

The ability to expand keratinocytes and construct dermal substitutes with cultured fibroblasts in vitroallows the formation of permanent coverage for large and deep wounds. Application of skin substitutes on full-thickness wound models of athymic mice showed complete closure of wounds, with stable engraftment and minimal scar formation [53]. Co-culture of keratinocytes and fibroblasts results in formation of granulation tissue that stimulates wound tissue remodeling. Chermnykh et al.[54] developed a bioengineered skin substitute from collagen scaffold seeded with skin cells that resulted in the formation of highly vascularized granulation-like tissue in the dermal compartment; rapid epithelialization was also reported when transplanted into full-thickness excisional splinting wounds in a murine model. Stem cells have been widely used in wound tissue regeneration and for the construction of skin equivalents. A recent study demonstrated the efficacy of artificial skin constructed by seeding adipose tissue-derived mesenchymal stromal cells (MSCs) on the decellularized human amniotic membrane and electrospun nanofibrous silk fibroin-based bilayer scaffold in a murine model of the burn wound [55]. Accelerated wound healing through enhanced neovascularization and re-epithelialization was observed along with hair follicle formation. Efforts have been made to increase the efficacy of transplanted stem cells. For example, increased proliferation and colony formation ability of mouse bone marrow-derived MSC and hematopoietic stem/progenitor cells were observed after exposure to a low concentration of the reactive oxygen species hydrogen peroxide, which resulted in JNK-FOXO3a signaling pathway activation. This led to the nuclear translocation and binding of FOXO3a to the catalase promoter, resulting in activation of catalase gene expression and the Akt-dependent proliferation pathway, which was perturbed by the catalase inhibitor. Transplantation of both bone marrow-derived MSC and hematopoietic stem/progenitor cells pre-conditioned with low levels of hydrogen peroxide led to increased engraftment and survival of the transplanted cells in an excisional splint wound healing murine model [56].

Transplanted stem cells often fail to regenerate wound tissue into functional skin because of their inability to differentiate. It has been observed that inhibition of cyclooxygenase 2 (Cox-2) in bone marrow stem cells results in enhanced differentiation into keratinocytes, reepithelialization and engraftment at the wound site via downregulation of Cox-2/IL-17-mediated inflammation [57]. Similarly, Cox-2 inhibition potentiates transdifferentiation of Wharton's jelly-derived MSCs (WJ-MSCs) into endothelial cells, which results in enhanced neovascularization at the wound bed after transplantation [58]. Recent studies have also reported the increased potency of genetically modified stem cells in wound tissue regeneration. Using a stem cell gene therapy approach, intravenous transplantation of MSCs overexpressing Cxcr6 led to increased skin regeneration in type 1 and 2 diabetic mice with excisional splint wounds [59]. Interestingly, the endothelial lineage commitment of WJ-MSCs was increased by TWIST1 reprogramming. It also increased the vasculogenic potential of reprogrammed endothelial cells. Transplantation of stable TWIST1reprogrammed endothelial cells into a type 1 and 2 diabetic fullthickness excisional splint wound healing murine model enhanced the microcirculatory blood flow and accelerated wound tissue regeneration [60]. In a recent study, genetically modified bone marrow stromal cells that continuously expressed TGF- $\beta 3$ were incorporated into tissue-engineered dermal equivalents to reduce scar tissue formation during wound healing [61]. After transplantation into fullthickness wounds of rats, these dermal equivalents showed decreased angiogenesis that did not affect wound healing but reduced scar formation. Integration of stem cell-based therapy and advanced tissue engineering processes can provide a promising tool for regenerative therapy in the future.

\section{Clinical advancement of skin equivalents in wound healing therapies}

The literature suggests that 3D skin equivalents were one of the first tissue-engineered organs to be used for clinical trials. The first organotypic culture of skin was demonstrated by Rheinwald and Green [62] by culturing human keratinocytes obtained from skin biopsies as epithelial sheets on a fibroblast (3T3 cells) layer, resulting in the formation of stratified epithelial-like structures, which were later used in several clinical trials. Autologous cells have been used to form human epithelium in vitro to provide permanent coverage for burn wound victims [63]. Over the years, bioengineered wound dressings and skin substitutes have been widely used in clinical therapies, and many of these have been made commercially available (Table 3). One of most extensively used acellular dermal substitutes, Integra ${ }^{\circledR}$, is used as wound dressing in burn and chronic wound patients and composed of silicone and collagen and/or glycosaminoglycan. Biobrane ${ }^{\circledR}$ is another acellular wound dressing of similar composition used for the treatment of burn wounds and genetic skin diseases (Table 3). Although these are widely used in the treatment of burn injuries, some reports suggest scar, serotome or hematoma formation as well as accumulation of exudate or wound secretion [64-66]. Some dermal substitutes like Dermagraft and TransCyte were constructed by seeding neonatal foreskin fibroblasts [67-69]. Allografts of human amniotic membrane such as GrafixPL PRIME and Affinity have also been used for wound healing therapies. However, since these are allogeneic materials, there is a possibility of infectious disease transmission to patients (ClinicalTrials.gov identifiers NCT02461641, NCT03742440). Bilayer composite skin equivalents resembling native human skin, like Apligraf, OrCel and StrataGraft, composed of living dermal and epidermal components are commonly used in clinical practices [70-73]. However, patients allergic to bovine products are not suitable for undergoing transplantation therapy with skin substitutes based on bovine collagen. In StrataGraft, the dermal equivalent is prepared using a non-bovine source of collagen (Table 3). A recent clinical investigation in which StrataGraft was compared with autografts for the treatment of burn wounds demonstrated no significant difference between the outcomes of the two treatment strategies. This suggests that StrataGraft can successfully replace autografts for wound tissue regeneration [74]. However, autografting still remains the preferred method for burn injuries affecting more than $50 \%$ of total body surface area.

Boyce et al.[75,76] developed an autologous engineered skin substitute (ESS) by culturing patient keratinocytes and fibroblasts obtained from biopsies on collagen-glycosaminoglycan scaffolds. Results of clinical trials suggest that this reduced the requirement of autografts for burn wound closure since ESS demonstrated higher expansion when compared with autografts. Therefore, a small area (less than $1 \%$ of total body surface area) of skin biopsy is needed for the generation of ESSESS, which can be expanded to cover larger burn wound surfaces. Boa et al. demonstrated the treatment of chronic venous and mixed ulcer patients with tissue-engineered skin substitutes combined with compression therapy. Wounds that were initially unresponsive to the standard compression therapy showed complete healing with a second course of treatment with skin substitutes [77]. Recently, a phase 1 clinical trial was conducted with 10 children with partial- or full-thickness skin defects [78]. Bioengineered skin grafts using autologous keratinocytes and fibroblasts incorporated into a collagen hydrogel were transplanted. Well-stratified epidermis and dermal compartment comparable to native skin 
were observed after 3 months of transplantation. In a randomized clinical trial conducted with patients with chronic diabetic wounds, skin substitutes prepared from WJ-MSCs seeded on acellular amniotic membrane were transplanted [79]. Wound size and wound healing time were reported to be significantly reduced in treated patients. Another study demonstrated the efficacy of fetal fibroblast-based skin substitutes in patients with burn wounds [80].

\section{Discussion}

Skin is a complex structure comprising a plethora of cells, connective tissue and appendages, including sweat glands, sebaceous glands and hair follicles. The morphological and physiological properties of skin are better represented in 3D cell culture systems when compared with 2D cell cultures. One of the first reported 3D cell culture systems of skin was the human skin biopsy culture, which encountered numerous challenges, such as ethical constraints and limited tissue availability, necessitating the development of skin equivalents. Spheroid cultures are not commonly used in the generation of skin equivalents. However, they have been used to develop melanoma models of skin. One of the key limitations of spheroids is the lack of a well-developed stratified epithelium. The most common method of skin equivalent formation is the layer-by-layer co-culture method wherein keratinocytes are seeded on top of cultured fibroblast cells. Recent advancements in tissue engineering have led to the utilization of biocompatible natural or synthetic scaffolds, which can provide adequate ECM components and can also be used to form dermal equivalents. However, in such culture systems, the cross-talks between dermal and epidermal components are difficult to reproduce, which limits the functionality of artificially produced skin. Bioprinting techniques have been developed recently to produce multilayered skin substitutes suitable for industrial, pre-clinical and clinical applications. Three-dimensional skin equivalents are used to study the unique properties of skin, such as epithelialization, formation of hair follicles and appendages, barrier function and senescence. Skin substitutes also serve as promising models for highly complex skin diseases, including psoriasis, atopic dermatitis, cutaneous candidiasis, pathogenic bacterial colonization and skin cancer.

\section{Conclusions}

Significant progress has been made recently in the development of artificial skin substitutes suitable for transplantation therapy in cases of serious injuries such as burn wounds and chronic diabetic wounds. Several successful attempts have been made to transplant bioengineered skin in patients. However, most of these transplants are only epidermal or dermal components or acellular matrices seeded with patients' cells. Most of the current protocols are not fully standardized and are time-consuming. Development of fully functional skin substitutes comprising all layers of the skin and its appendages for clinical applications still requires more research and development.

\section{Funding}

AD acknowledges funding provided by the Council of Scientific and Industrial Research, Ministry of Science and Technology, Government of India for Niche Creating High Science Projects under Healthcare theme (CSIR-IICT MLP0053 [GRAFT]). Fellowship provided by UGC-JRF/SRF to SC is gratefully acknowledged (manuscript communication no. IICT/Pubs.(2020/133).

\section{Author Contributions}

Conception and design of the study: AD. Acquisition of data: SC. Analysis and interpretation of data: AD and SC. Drafting or revising the manuscript: AD and SC. All authors have approved the final article.

\section{Declaration of Competing Interest}

The authors have no commercial, proprietary or financial interest in the products or companies described in this article.

\section{References}

1] Pailler-Mattei C, Nicoli S, Pirot F, Vargiolu R, Zahouani H. A new approach to describe the skin surface physical properties in vivo. Colloids and Surfaces B: Biointerfaces 2009;68(2):200-6

[2] Edqvist PHD, Fagerberg L, Hallström BM, Danielsson A, Edlund K, Uhlén M, Pontén F. Expression of human skin-specific genes defined by transcriptomics and antibody-based profiling. Journal of Histochemistry \& Cytochemistry 2015;63 (2):129-41.

[3] Medawar PB. The cultivation of adult mammalian skin epithelium in vitro. Journal of Cell Science 1948:3(6):187-96

[4] Bell E, Ehrlich HP, Buttle DJ, Nakatsuji T. Living tissue formed in vitro and accepted as skin-equivalent tissue of full thickness. Science 1981;211(4486):1052-4.

[5] Foty R. A simple hanging drop cell culture protocol for generation of 3D spheroids. JoVE (Journal of Visualized Experiments) 2011;51:e2720.

[6] Klicks J, Maßlo C, Kluth A, Rudolf R, Hafner M. A novel spheroid-based co-culture model mimics loss of keratinocyte differentiation, melanoma cell invasion, and drug-induced selection of ABCB5-expressing cells. BMC Cancer 2019;19(1):402.

[7] Michel M, L'Heureux N, Pouliot R, Xu W, Auger FA, Germain L. Characterization of a new tissue-engineered human skin equivalent with hair. In Vitro Cellular \& Developmental Biology - Animal 1999;35(6):318-26.

[8] Liu Y, Luo H, Wang X, Takemura A, Fang YR, Jin Y, Suwa F. In vitro construction of scaffold-free bilayered tissue-engineered skin containing capillary networks, BioMed Research International 2013;2013:561410.

[9] Kim Y, Park N, Rim YA, Nam Y, Jung H, Lee K, Ju JH. Establishment of a complex skin structure via layered co-culture of keratinocytes and fibroblasts derived from induced pluripotent stem cells. Stem Cell Research \& Therapy 2018;9(1): $1-10$.

[10] Miyazaki H, Tsunoi Y, Akagi T, Sato S, Akashi M, Saitoh D. A novel strategy to engineer pre-vascularized 3-dimensional skin substitutes to achieve efficient, functional engraftment. Scientific Reports 2019;9(1):1-10.

[11] Casale C, Imparato G, Urciuolo F, Rescigno F, Scamardella S, Escolino M, Netti PA. Engineering a human skin equivalent to study dermis remodelling and epidermis senescence in vitro after UVA exposure. Journal of Tissue Engineering and Regenerative Medicine 2018;12(7):1658-69.

[12] Chan EC, Kuo SM, Kong AM, Morrison WA, Dusting GJ, Mitchell GM, Lim SY, Liu GS. Three dimensional collagen scaffold promotes intrinsic vascularisation for tissue engineering applications. PLoS One 2016;11(2):e0149799.

[13] Reuter C, Walles H, Groeber F. Preparation of a Three-Dimensional Full Thickness Skin Equivalent. Methods in Molecular Biology 2017;1612:191-8.

[14] Liu H, Mao J, Yao K, Yang G, Cui L, Cao Y. A study on a chitosan-gelatin-hyaluronic acid scaffold as artificial skin in vitro and its tissue engineering applications. J Biomater Sci Polym Ed 2004;15(1):25-40.

[15] Singaravelu S, Ramanathan G, Raja MD, Nagiah N, Padmapriya P, Kaveri K, Sivagnanam UT. Biomimetic interconnected porous keratin-fibrin-gelatin 3D sponge for tissue engineering application. International Journal of Biological Macromolecules 2016;86:810-9.

[16] Shalumon KT, Sathish D, Nair SV, Chennazhi KP, Tamura H, Jayakumar R. Fabrication of aligned poly (lactic acid)-chitosan nanofibers by novel parallel blade collector method for skin tissue engineering. Journal of Biomedical Nanotechnology 2012;8(3):405-16.

[17] Sekiya N, Ichioka S, Terada D, Tsuchiya S, Kobayashi H. Efficacy of a poly glycolic acid (PGA)/collagen composite nanofibre scaffold on cell migration and neovascularisation in vivo skin defect model. Journal of Plastic Surgery and Hand Surgery 2013;47(6):498-502.

[18] Lee PY, Cobain E, Huard J, Huang L, Thermosensitive hydrogel PEG-PLGA-PEC enhances engraftment of muscle-derived stem cells and promotes healing in diabetic wound. Molecular Therapy 2007;15(6):1189-94.

[19] Geesala R, Bar N, Dhoke NR, Basak P, Das A. Porous polymer scaffold for on-site delivery of stem cells-protects from oxidative stress and potentiates wound tissue repair. Biomaterials 2016;77:1-13.

[20] Roger MM, Fullard N, Costello L, Bradbury SG, Markiewicz E, O'Reilly S, Darling N, Ritchie PF, Määttä A, Karakesisoglou I, Nelson G, Zglinicki TV, DiColandrea T, Isfort RJ, Bascom CC, Przyborski S. Bioengineering the microanatomy of human skin. Journal of Anatomy 2019;234:438-55.

[21] Matsusaki M, Sakaue K, Kadowaki K, Akashi M. Three-dimensional human tissue chips fabricated by rapid and automatic inkjet cell printing. Advanced Healthcare Materials 2013;2(4):534-9.

[22] Michael S, Sorg H, Peck CT, Koch L, Deiwick A, Chichkov B, Vogt PM, Reimers K. Tissue engineered skin substitutes created by laser-assisted bioprinting form skin-like structures in the dorsal skin fold chamber in mice. PLoS One 2013;8(3): e57741.

[23] Sakai S, Ohi H, Hotta T, Kamei H, Taya M. Differentiation potential of human adipose stem cells bioprinted with hyaluronic acid/gelatin-based bioink through 
microextrusion and visible light-initiated crosslinking. Biopolymers 2018;109 (2):e23080.

[24] Kim BS, Lee JS, Gao G, Cho DW. Direct 3D cell-printing of human skin with functional transwell system. Biofabrication 2017;9(2):025034.

[25] Kim BS, Gao G, Kim JY, Cho DW. 3D Cell Printing of Perfusable Vascularized Human Skin Equivalent Composed of Epidermis, Dermis, and Hypodermis for Better Structural Recapitulation of Native Skin. Advanced Healthcare Materials 2019;8(7):e1801019.

[26] Cubo N, Garcia M, delCañizo JF, Velasco D, Jorcano JL. 3D bioprinting of functional human skin: production and in vivo analysis. Biofabrication 2016;9(1):015006.

[27] Kim BS, Kwon YW, Kong JS, Park GT, Gao G, Han W, Kim NB, Lee H, Kim JH, Cho DW. 3D cell printing of in vitro stabilized skin model and in vivo pre-vascularized skin patch using tissue-specific extracellular matrix bioink: a step towards advanced skin tissue engineering. Biomaterials 2018;168:38-53.

[28] Min D, Lee W, Bae IH, Lee TR, Croce P, Yoo SS. Bioprinting of biomimetic skin containing melanocytes. Experimental Dermatology 2018;27(5):453-9.

[29] Derr K, Zou J, Luo K, Song MJ, Sittampalam GS, Zhou C, Michael S, Ferrer M, Derr P. Fully three-dimensional bioprinted skin equivalent constructs with validated morphology and barrier function. Tissue Engineering Part C: Methods 2019;25 (6):334-43.

[30] Lalley AL, Boyce ST. Fabrication of Chimeric Hair Follicles for Skin Tissue Engineering. Skin Tissue Engineering. New York, NY, USA: Humana Press; 2019. p. 159-79.

[31] Vahav I, van den Broek LJ, Thon M, Monsuur HN, Spiekstra SW, Atac B, Scheper RJ, Lauster R, Lindner G, Marx U, Gibbs S. Reconstructed human skin shows epidermal invagination towards integrated neopapillae indicating early hair follicle formation in vitro. Journal of Tissue Engineering and Regenerative Medicine 2020;14 (6):761-73.

[32] Shikiji T, Minami M, Inoue T, Hirose K, Oura H, Arase S. Keratinocytes can differentiate into eccrine sweat ducts in vitro: involvement of epidermal growth factor and fetal bovine serum. Journal of Dermatological Science 2003;33(3):141-50.

[33] Huang S, Xu Y, Wu C, Sha D, Fu X. In vitro constitution and in vivo implantation of engineered skin constructs with sweat glands. Biomaterials 2010;31(21):5520-5.

[34] Diekmann J, Alili L, Scholz O, Giesen M, Holtkötter O, Brenneisen P. A three-dimensional skin equivalent reflecting some aspects of in vivo aged skin. Experimental Dermatology 2016;25(1):56-61.

[35] Weinmüllner R, Zbiral B, Becirovic A, Stelzer EM, Nagelreiter F, Schosserer M, Lämmermann I, Liendl L, Lang M, Terlecki-Zaniewicz L, Andriotis O. Organotypic human skin culture models constructed with senescent fibroblasts show hallmarks of skin aging. NPJ Aging and Mechanisms of Disease 2020;6(1):1-7.

[36] Mieremet A, Helder R, Nadaban A, Gooris G, Boiten W, El Ghalbzouri A, Bouwstra JA. Contribution of Palmitic Acid to Epidermal Morphogenesis and Lipid Barrier Formation in Human Skin Equivalents. International Journal of Molecular Sciences 2020;20(23):6069.

[37] Mieremet A, García AV, Boiten W, van Dijk R, Gooris G, Bouwstra JA, El Ghalbzouri A. Human skin equivalents cultured under hypoxia display enhanced epidermal morphogenesis and lipid barrier formation. Scientific Reports 2019;9(1):7811.

[38] Yuki T, Tobiishi M, Kusaka-Kikushima A, Ota Y, Tokura Y. Impaired tight junctions in atopic dermatitis skin and in a skin-equivalent model treated with interleukin17. PLoS One 2016;11(9):e0161759.

[39] Yuki T, Komiya A, Kusaka A, Kuze T, Sugiyama Y, Inoue S. Impaired tight junctions obstruct stratum corneum formation by altering polar lipid and profilaggrin processing. Journal of Dermatological Science 2013;69(2):148-58.

[40] Huth S, Schmitt L, Marquardt Y, Heise R, Lüscher B, Amann PM, Baron JM. Effects of a ceramide-containing water-in-oil ointment on skin barrier function and allergen penetration in an IL-31 treated 3D model of the disrupted skin barrier. Experimental Dermatology 2018;27(9):1009-14.

[41] Lorthois I, Simard M, Morin S, Pouliot R. Infiltration of T Cells into a Three-Dimensional Psoriatic Skin Model Mimics Pathological Key Features. International Journal of Molecular Sciences 2019;20(7):1670.

[42] Shin JU, Abaci HE, Herron L, Guo Z, Sallee B, Pappalardo A, Jackow J, Wang EHC, Doucet Y, Christiano AM. Recapitulating T cell infiltration in 3D psoriatic skin models for patient-specific drug testing. Scientific Reports 2020;10(1):1-12.

[43] Clarysse K, Pfaff CM, Marquardt Y, Huth L, KortekaasKrohn I, Kluwig D, Lüscher B, Gutermuth J, Baron J. JAK1/3 inhibition preserves epidermal morphology in full-thickness 3D skin models of atopic dermatitis and psoriasis. Journal of the European Academy of Dermatology and Venereology 2019;33(2):367-75.

[44] De Vuyst E, Giltaire S, Lambert de Rouvroit C, Malaisse J, Mound A, Bourtembourg M, Nikkels AF, Chretien A, Salmon M, Poumay Y. MbCD concurs with IL-4, IL-13 and IL-25 to induce alterations reminiscent of atopic dermatitis in reconstructed human epidermis. Experimental Dermatology 2016;27(4):435-7.

[45] do Nascimento Pedrosa T, De Vuyst E, Mound A, De Rouvroit CL, Maria-Engler SS, Poumay Y. Methyl- $\beta$-cyclodextrin treatment combined to incubation with interleukin-4 reproduces major features of atopic dermatitis in a 3D-culture model. Archives of Dermatological Research 2017;309(1):63-9.

[46] Liu X, Michael S, Bharti K, Ferrer M, Song MJ. A biofabricated vascularized skin model of atopic dermatitis for preclinical studies. Biofabrication 2020;12 (3):035002

[47] Hill DS, Robinson ND, Caley MP, Chen M, O'Toole EA, Armstrong JL, Przyborski S, Lovat PE. A novel fully humanized 3D skin equivalent to model early melanoma invasion. Molecular Cancer Therapeutics 2015;14(11):2665-73.

[48] Bourland J, Fradette J, Auger FA. Tissue-engineered 3D melanoma model with blood and lymphatic capillaries for drug development. Scientific Reports 2018;8 (1):1-13.

[49] Korting HC, Patzak U, Schaller M, Maibach HI. A model of human cutaneous candidosis based on reconstructed human epidermis for the light and electron microscopic study of pathogenesis and treatment. Journal of Infection 1998;36(3):259-67.
[50] Schaller M, Preidel H, Januschke E, Korting HC. Light and electron microscopic findings in a model of human cutaneous candidosis based on reconstructed human epidermis following the topical application of different econazole formulations. Journal of Drug Targeting 1999;6(5):361-72.

[51] Lerebour G, Cupferman S, Bellon-Fontaine MN. Adhesion of Staphylococcus aureus and Staphylococcus epidermidis to the EpiskinR reconstructed epidermis model and to an inert 304 stainless steel substrate. Journal of Applied Microbiology 2004;97(1):7-16

[52] Holland DB, Bojar RA, Jeremy AH, Ingham E, Holland KT. Microbial colonization of an in vitro model of a tissue engineered human skin equivalent-a novel approach. FEMS Microbiology Letters 2008;279(1):110-5.

[53] Kalyanaraman B, Boyce ST. Wound healing on athymic mice with engineered skin substitutes fabricated with keratinocytes harvested from an automated bioreactor. Journal of Surgical Research 2009;152(2):296-302.

[54] Chermnykh ES, Kiseleva EV, Rogovaya OS, Rippa AL, Vasiliev AV, Vorotelyak EA. Tissue-engineered biological dressing accelerates skin wound healing in mice via formation of provisional connective tissue. Histology and Histopathology 2018;30:18006.

[55] Gholipourmalekabadi M, Seifalian AM, Urbanska AM, Omrani MD, Hardy JG, Madjd Z, Hashemi SM, Ghanbarian H, Brouki Milan P, Mozafari M, Reis RL. 3D protein-based bilayer artificial skin for the guided scarless healing of third-degree burn wounds in vivo. Biomacromolecules 2018;19(7):2409-22.

[56] Dhoke NR, Geesala R, Das A. Low oxidative stress-mediated proliferation Via JNKFOXO3a-catalase signaling in transplanted adult stem cells promotes wound tissue regeneration. Antioxidants \& Redox Signaling 2018;28(11):1047-65.

[57] Geesala R, Dhoke NR, Das A. Cox-2 inhibition potentiates mouse bone marrow stem cell engraftment and differentiation-mediated wound repair. Cytotherapy 2017;19(6):756-70.

[58] Kaushik K, Das A. Cycloxygenase-2 inhibition potentiates trans-differentiation of Wharton's jelly-mesenchymal stromal cells into endothelial cells: transplantation enhances neovascularization-mediated wound repair. Cytotherapy 2019;21 (2):260-73.

[59] Dhoke NR, Kaushik K, Das A. CXCR6-based mesenchymal stem cell gene therapy potentiates skin regeneration in murine diabetic wounds. Molecular Therapy 2020;28(5):1314-26.

[60] Kaushik K, Das A. TWIST1-Reprogrammed Endothelial Cell Transplantation Potentiates Neovascularization-Mediated Diabetic Wound Tissue Regeneration. Diabetes 2020;69(6):1232-47.

[61] Samadikuchaksaraei A, Mehdipour A, Habibi Roudkenar M, Verdi J, Joghataei MT, As' adi K, Amiri F, Dehghan Harati M, Gholipourmalekabadi M, Karkuki Osguei N. A dermal equivalent engineered with TGF- $\beta 3$ expressing bone marrow stromal cells and amniotic membrane: cosmetic healing of full-thickness skin wounds in rats. Artificial Organs 2016;40(12):E266-79.

[62] Rheinwald JG, Green H. Serial cultivation of strains of human epidermal keratinocytes: the formation of keratinizing colonies from single cells. Cell 1975;6 (3):331-43.

[63] O'Connor N, Mulliken J, Banks-Schlegel S, Kehinde O, Green H. Grafting of burns with cultured epithelium prepared from autologous epidermal cells. The Lancet 1981:317(8211):75-8.

[64] Stiefel D, Schiestl C, Meuli M. Integra Artificial Skin ${ }^{\circledR}$ for burn scar revision in adolescents and children. Burns 2010;36(1):114-20.

[65] Yao M, Attalla K, Ren Y, French MA, Driver VR. Ease of use, safety, and efficacy of Integra bilayer wound matrix in the treatment of diabetic foot ulcers in an outpatient clinical setting: a prospective pilot study. Journal of the American Podiatric Medical Association 2013;103(4):274-80.

[66] Jutkiewicz J, Noszczyk BH, Wrobel M. The use of Biobrane for hand surgery in epidermolysis bullosa. J Plast Reconstr Aesthet Surg 2010;63(8):1305-11.

[67] Marston WA, Hanft J, Norwood P, Pollak R. The efficacy and safety of Dermagraft in improving the healing of chronic diabetic foot ulcers: results of a prospective randomized trial. Diabetes Care 2003;26(6):1701-5.

[68] Noordenbos J, Doré C, Hansbrough JF. Safety and efficacy of TransCyte ${ }^{\circledR}$ for the treatment of partial-thickness burns. Journal of Burn Care \& Rehabilitation 1999;20(4):275-81.

[69] Amani H, Dougherty WR, Blome-Eberwein S. Use of Transcyte ${ }^{\circledR}$ and dermabrasion to treat burns reduces length of stay in burns of all size and etiology. Burns 2006;32(7):828-32.

[70] Hu S, Kirsner RS, Falanga V, Phillips T, Eaglstein WH. Evaluation of Apligraf ${ }^{\circledR}$ persistence and basement membrane restoration in donor site wounds: a pilot study. Wound Repair and Regeneration 2006;14(4):427-33.

[71] Falabella AF, Valencia IC, Eaglstein WH, Schachner LA. Tissue-engineered skin (Apligraf) in the healing of patients with epidermolysis bullosa wounds. Archives of Dermatology 2000;136(10):1225-30.

[72] Still J, Glat P, Silverstein P, Griswold J, Mozingo D. The use of a collagen sponge/ living cell composite material to treat donor sites in burn patients. Burns 2003;29 (8):837-41.

[73] Schurr MJ, Foster KN, Centanni JM, Comer AR, Wicks A, Gibson AL, Thomas-Virnig CL, Schlosser SJ, Faucher LD, Lokuta MA, Allen-Hoffmann BL. Phase I/II clinical evaluation of StrataGraft: a consistent, pathogen-free human skin substitute. The Journal of Trauma 2009;66(3):866-74.

[74] Holmes IV JH, Schurr MJ, King BT, Foster K, Faucher LD, Lokuta MA, Comer AR, Rooney PJ, Barbeau KF, Mohoney ST, Gibson AL, open-label An, prospective randomized, controlled multicenter. An open-label, prospective, randomized, controlled, multicenter, phase $1 \mathrm{~b}$ study of StrataGraft skin tissue versus autografting in patients with deep partial-thickness thermal burns. Burns 2019;45(8):1749-58.

[75] Boyce ST, Kagan RJ, Yakuboff KP, Meyer NA, Rieman MT, Greenhalgh DG, Warden GD. Cultured skin substitutes reduce donor skin harvesting for closure of excised, full-thickness burns. Annals of Surgery 2002;235(2):269. 
[76] Boyce ST, Simpson PS, Rieman MT, Warner PM, Yakuboff KP, Bailey JK, Nelson JK, Fowler LA, Kagan RJ. Randomized, paired-site comparison of autologous engineered skin substitutes and split-thickness skin graft for closure of extensive, full-thickness burns. Journal of Burn Care \& Research 2017;38(2):61-70.

[77] Olivier B, Beaudoin CC, Hervé G, Raymond L, Bertrand R, Jacques S, Michel R, Frédéric A, Carlos E. O, Nathalie D, Marie-Hélène R, Danielle L, Véronique J. M, Lucie G, Auger FA. Prospective study on the treatment of lower-extremity chronic venous and mixed ulcers using tissue-engineered skin substitute made by the self-assembly approach. Advances in Skin \& Wound Care 2013;26(9):400-9.

[78] Meuli M, Hartmann-Fritsch F, Hüging M, Marino D, Saglini M, Hynes S, Neuhaus K, Manuel E, Middelkoop E, Reichmann E, Schiestl C. A Cultured Autolo- gous Dermo-epidermal Skin Substitute for Full-Thickness Skin Defects: A Phase I, Open, Prospective Clinical Trial in Children. Plastic and Reconstructive Surgery 2019;144(1):188-98.

[79] Hashemi SS, Mohammadi AA, Kabiri H, Hashempoor MR, Mahmoodi M, Amini M, Mehrabani D. The healing effect of Wharton's jelly stem cells seeded on biological scaffold in chronic skin ulcers: a randomized clinical trial. Journal of Cosmetic Dermatology 2019;18(6):1961-7.

[80] Momeni M, Fallah N, Bajouri A, Bagheri T, Orouji Z, Pahlevanpour P, Shafieyan S, Sodeifi N, Alizadeh A, Aghdami N, Fatemi MJ. A randomized, double-blind, phase clinical trial of fetal cell-based skin substitutes on healing of donor sites in burn patients. Burns 2019;45(4):914-22. 